\title{
open access and academic
} associations in the political and social sciences: threat or opportunity?

martin j. bull

School of Arts \& Media, University of Salford, Salford M5 4WT, UK

E-mail: m.j.bull@salford.ac.uk

doi:10.1057/eps.2015.88; published online 15 January 2016

\begin{abstract}
Academic associations are a vital part of the academic community, facilitating the interaction of researchers and production of knowledge, yet the impact of Open Access on their future has been too often regarded as marginal to the main discussion. Open Access presents an evident threat to those associations, which have become dependent upon a sizeable proportion of their income coming from owned journals published in conjunction with publishers. Yet, Open Access also presents opportunities, and academic associations should be bold in using a combination of their expertise, prestige and experience in publishing to ensure their futures in a newly emerging market.
\end{abstract}

Keywords open access; academic associations; learned societies; social science; political science; journals

The online version of this article is available Open Access

A cademic associations or learned societies play a fundamental role in many social scientists' careers, and even those who do not use them are certain to be indirectly benefited by their existence. Whether it is attending a conference or workshop, attending a Ph.D. or a Summer School, drawing on research published in a journal or a book, listening to a keynote lecture, lobbying government and so on, academic associations are invariably often at the heart of an academic's activities, facilitating, in organizational and other ways, interaction with others and the production of research and teaching. Academic associations articulate, protect and enhance academic interests in ways that supplement or reinforce - rather than undermine - the role played by their employers (universities) and trade unions in relation to their working conditions and performance. They oil 
the academic machine, especially by enhancing the quality of interaction between academics in different national and international settings. In the absence (to this author's knowledge) of any commonly-accepted definitions of academic associations or professional societies we can propose the following as a working definition:

An association of individuals or institutions (or both) which are almost exclusively academic, and which exist in order to facilitate the development of a defined disciplinary, sub-disciplinary or multi-disciplinary area, through a range of activities of a supportive, facilitative and interactive nature, including: organizing conferences and workshops, running training programmes, supporting the mobility of researchers, inviting prestigious speakers, designing and giving out prizes and awards, representing and lobbying government and public bodies, disseminating research through publishing activities, and any other activities which further the research and teaching interests of the area.

It should immediately be noted that this definition encompasses a wide variety of academic associations. They range from small sub-disciplinary or multidisciplinary associations which might have no permanent staff and simply run an annual conference or focus their activities around a journal, to the large national and cross-national associations - such as the American Political Science Association (APSA), the UK Political Studies Association (PSA) and the European Consortium of Political Research - which have significant financial turnover, permanent staff and a large range of activities, and which usually involve publishing ventures, especially journals (see, for example, ECPR, 2015).

Seen in this light, it is curious that the implications of Open Access (OA) for academic associations and possible solutions

\section{'[Academic associations] oil the academic machine...'}

to the dilemmas posed have not figured more prominently in the debate. From the perspective of those campaigning for $O A$, it may be that the future or fortunes of academic associations under OA are largely irrelevant because of the 'rightness' of the OA cause. From the perspective of those implementing $O A$, it is not clear how aware government and its representatives are of the importance of academic associations to academic and publishing life. In the United Kingdom, for example, one of the countries where significant regulatory, legislative action has occurred, ignorance about the role of academic associations seems clear, despite the Finch (working group) report (on which the government had acted) having raised concerns about the implications for academic associations under OA (Working group on expanding access to published research findings, 2012: 91). It could also be argued that $O A$ has not consistently been given the attention it deserves by academic associations themselves, at least in the social sciences and humanities, which - in contrast with some areas of the sciences - have arrived 'late' to the OA party.

Yet, the implications of OA for academic associations are potentially very significant, simply because their development and growth has owed much to their activities in setting up journals, finding publishers to publish and distribute those journals, and reaping the financial rewards of doing so. It follows that, if moves toward OA were to entail - as widely feared - a drop in the financial return to academic associations, then these associations are facing a marked change in their circumstances and business models which need to be confronted. In confronting them, these associations need also to assess the extent to 
which OA might also present opportunities to be exploited. This article therefore analyses the implications of OA from two perspectives: the threat $O A$ poses and the opportunities it might present.

\section{OA AND ACADEMIC ASSOCIATIONS: THE THREAT}

The business model of most academic associations is based on generating income through three routes: membership fees, conference fees and publishing activities. The last of these has been critical to the bigger associations and, to a large extent explains their growth, because income generated through the arrangements with publishers has allowed the associations both to keep membership and conference fees relatively low (and therefore membership numbers and attendance at conferences high) and expand the range of services that can be offered to members. Between 1970 and 1997 the cost of institutional subscriptions to journals rose by an average of 13 per cent a year (they were 30 times more expensive in 1997) (Beverungen et al, 2012). This is not, of course, all down to increased profit. On the contrary, there has been a veritable transformation of what journals look like in terms of size, offering, formats, delivery and so on, which has required significant investments on the part of publishers. Nevertheless, the constant increase in subscription costs has led to a decline in the average number of subscriptions, which has been offset by the growth in new journals, so that there are now more journals each with fewer subscriptions. Overall, in the past two decades it is estimated that the number of journals has grown by 200-300 per year, with the existence of about 16,000 academic journals today (Beverungen et al, 2012). Consequently, for those academic associations owning their own journals, income from journal subscriptions (and specifically institutional subscriptions) has risen steeply over the years (and almost certainly more steeply than membership and conference fees). For example, one of the richest national political science associations, the UK's PSA, saw income from the publisher of its journals rise from $£ 126,084$ in 2000 to $£ 511,279$ in $2014 .^{1}$

It is therefore the existence of academic associations' publishing activity which creates an inherent dilemma for many of these associations. On the one hand, seen in purely theoretical terms (as a blueprint of an 'ideal society'), it is difficult to argue in principle against $O A$. If one of the goals of academic associations is to disseminate knowledge about its disciplinary area, then it seems inherently difficult to support a system of pay walls and barriers to access put in place by publishers. OA promises, on all counts, to make research more widely and immediately available to the academic community and beyond. For those most passionate about a rapid and wholesale transition to $\mathrm{OA}$, then, the case is made.

On the other hand, many academic associations are confronted by the reality that they have made significant financial gains from their publishing activities and that $O A$ threatens to undermine those gains. Looking at the maths, it is clear that the likely income that can be generated from Article Processing Charges (APCs) is not going to match the levels of income generated through the traditional subscription model. One estimate is that the average income generated by an article is likely to drop from US $\$ 5,000$ in the subscription model to under $\$ 2,000$ in a Gold OA model (Esposito, 2013) (although that is not to say that the maths is necessarily simple in its scenarios - see, e.g., Velterop, 2005: 15-20). The UK's PSA, in its submission to the first independent review of the UK's Research Council's policy on OA, noted that 'If all the articles published in the PSA journals (based on 
2013 volumes) were published using the Gold model and we were to cease charging subscriptions, the total income generated by our four journals would fall by approximately 50 per cent. This would barely cover expenditure and publication would not be viable' (PSA, 2014: 1); this, moreover, for an association whose journals account for over 60 per cent of its income (ibid.). For some observers, the implications for academic associations are grim: 'A comprehensive OA paradigm ... is pretty much a frontal assault on professional societies ... perhaps it is time to acknowledge the twilight of the professional society' (Esposito, 2013).

The dilemma facing academic associations may explain the apparent reticence of many of them to engage more emphatically with the OA debate and take up a clear position in it. ${ }^{2}$ They are conscious that an argument that could be made (in theory) for OA threatens their ability to thrive, if not survive, in such a brave new world. This may also explain why academic associations have, to some extent been overlooked in the discussion, or worse, implicitly lumped in the same category as publishers, as organizations which have 'done well' out of the subscriptionbased model and whose fate in a world of $\mathrm{OA}$ is either deserved or of little interest.

Yet, there are notable differences between publishers and academic associations, if only in the level of vitriol often poured on the activities of the former, accused of appropriating public resources to feed their profits: 'The poverty of the current journal publishing system is one described by a double, even triple, appropriation of public resources. Universities pay for staff who write, review and edit journals for free; they then have to buy these journals back from the publishers at highly inflated prices. The result is that more and more journal content is stored behind the firewalls of for-profit publishing conglomerates, whereas the public, which has vested interests in seeing the

\section{'... many academic associations ... have made significant financial gains from their publishing activities and ... OA threatens to undermine those gains'.}

outcomes of (tax-payer funded, if not all) research, has little or no access to that knowledge' (Beverungen et al, 2012: 936). Meanwhile, it is the publishers who claim the intellectual property rights for the knowledge produced by the universities but do not recompense them for doing so. The profits the big publishers reap are in the region of 30-40 per cent, and their control over the market is strong. For example, Elsevier, Wiley, Springer, Kluwer and Informa together, controlled about 36 per cent of market share in 2009 (ibid.: 930-932).

Academic associations, of course, are not completely free from these sort of charges. They own a significant proportion of journals (many having started life as 'in-house' publishing projects of a largely primitive nature to test demand) produced with publishers, through which they have seen rising income, largely on the basis of rising subscription prices: and as annual price rises are based on an agreement between the two (the publisher proposing, the academic association approving), then academic associations must carry some responsibility for the price hikes over the past three decades.

Yet, at the same time, there is, of course, a significant difference between the two types of organization. Most publishers are commercial organizations (and perhaps it is odd to criticize them for doing what they are meant to do - make profit), while academic associations have, for the most part, charitable status. They are non-profit-making, and, therefore, any 
surpluses they make - beyond funding the running of the organization and maintaining a safe level of reserves - are (because they have to be) ploughed back into benefits for the members. In this way, the income generated by an academic association's publishing activities has been and is used to expand the range of services offered by the association to the discipline. Indeed, it could be argued that the academic associations which have become the biggest providers of services to their members are precisely those which have been able to generate income from publishing activities. ${ }^{3}$

There can be no doubt, therefore, that academia has benefited from the income made by academic associations from journal publishing. Moreover, while there is a growing debate over the value that publishers (in the world of the internet) bring to the publishing process itself ('We believe the publisher adds relatively little value to the publishing process': Deutsch Bank on Elsevier in 2005 - quoted in Monbiot, 2011), few question the vital role that academic associations play in facilitating the production of research by academics. It could be added, too, that where comparisons have been made, the price per page of journals owned and published by academic associations or university presses is 3-9 times less than those published by commercial publishers (Beverungen et al, 2012: 931), an indication, perhaps, of the absence of a 'profitmaking' instinct in the former. ${ }^{4}$

It follows that, if moves toward OA have implications for the capacity of academic associations to deliver their services, then - irrespective of the potential importance of $\mathrm{OA}$ to delivering their goals - it has to be looked at both cautiously and, if necessary, ambitiously. The question, in other words, may not be whether or not to support the idea of OA but rather how to reach OA without damaging irreparably what academic associations currently provide to the academic industry.
Because academic associations are nonprofit-making, there is no inherent dilemma in them accepting $O A$ (on the contrary, it meets their goals, as has been said), and if the world had developed in a different way (i.e., with OA at its heart at the outset) then academic associations would have carved out a vital role based on the levels of income generated by that model. However, many academic associations have built up their organizations on the basis of income generated by a different (subscription-based) model, and they have both a level of fixed costs and a range of activities shaped by that model, which are difficult, if not impossible, to undo or adjust overnight.

It is, therefore, probably less a question of whether or not to move toward OA than of the transitional costs for academic associations of doing so. It has been said that academic associations are not facing a fiscal cliff but certainly a fiscal slope, the steepness of which is difficult to identify or predict. That level of uncertainty is not a good position to be in. What therefore are the choices facing academic associations in this position?

\section{OA AND ACADEMIC ASSOCIATIONS: AN OPPORTUNITY?}

We can look at three possible scenarios for academic associations and how they might unfold, or are unfolding in the present climate, and specifically those associations which own journals and are currently in a publishing relationship with a publisher.

\section{SCENARIO ONE: STAYING WITH THE 'PURE' SUBSCRIPTION MODEL}

The first approach to consider would be simply to stay with the 'pure' subscription model. This is, however, by now largely a non-existent option, at least for those journals that academic associations 
publish in conjunction with commercial publishers or university presses. A 'pure' subscription-based model with no provision for any form of OA publishing, with or without APCs, is rare in journals today, has barely existed for some years, and is highly unlikely ever to exist again. If we take recent decisions of the UK government and its Research Councils as indicative of things to come elsewhere, then journals opting for 'pure' subscription and no provision for OA would be consigning themselves to an almost impossible future. Since research published in journals on the back of a Research Council funding grant or submitted for consideration in the 2020 Research Excellence Framework (the UK's re-named research assessment exercise) is required to appear in OA format, any journal, to be able to publish high-quality research by UK scholars, will have to make some provision for $O A$ publishing. The question, therefore, is less whether or not academic associations opt for OA than what exact form of OA they adopt.

\section{SCENARIO TWO: GOING FOR GOLD}

The second approach is for an academic association to transform its journal into one based on Gold OA, with APCs and no embargos. In short, authors would pay an APC up front and have their work accessible immediately, with journal income being derived from the APCs. For academic associations there are two possible routes to this. One would be without a publisher. In other words, where an academic association owns a journal, it takes it back into its own in-house publication, ending its relationship with the publisher and going it alone. The association then needs to consider the investments necessary to host the journal online in an accessible and user-friendly way, the cost of administering the journal and the APCs that would be necessary to sustain it. The other route would be Gold OA with a
'... a sizeable number of so-called predatory publishing ventures launching Open Access journals with the sole aim, it seems, of making money ...'

publisher, where (at the point of renewal of contract), a tender would be put out to publishers to bid for a Gold OA-only contract. That contract would probably have to be based on a different approach to sharing the costs and income than currently prevails.

This is not necessarily so risky if one considers what has been happening in the journals market, with the emergence of a sizeable number of so-called predatory publishing ventures launching OA journals with the sole aim, it seems, of making money, and where quality may consequently be sacrificed for money. ${ }^{5}$ Academic associations have a lot to offer in such a market with their existing highquality journals. With regard to drops in income, projections of life under OA are hazardous to say the least. On the one hand, on the basis of existing charges, it is evident that a journal based on APCs would generate only a fraction of the income it currently generates through subscriptions. On the other hand, would anyone have predicted in 1970 that journal subscription prices would, by 1997, increase in price thirty-fold? It should not, therefore, be assumed that APCs will remain static once and if a Gold OA regime establishes itself.

Yet, at the same time, it has to be recognized that for individual academic associations to take such a decision with their prestigious and income-generating journals would be a high risk option insofar as it would be a high-speed transition from one model to another, involving a shortterm dramatic, if not drastic, drop in 
income (possibly to nothing if APCs were to be waived for an initial period) and which would undermine the association's other important activities in supporting the academic profession. There are, in short, dangers in going too fast too soon - the industry needs to move roughly together.

\section{SCENARIO THREE: GOING GREEN ... AND GOLD?}

The third scenario is the one based on the (currently predominant) model of Green OA. Green OA allows authors to deposit their work in a repository (electronic archive) at the same time that it has been accepted for publication in a subscriptionbased journal, although this would ordinarily not be the publisher's version of record, but a pre-proof-corrected copy (or Author Accepted Manuscript, AAM). Repositories may be set up and run by the researcher's university or they may choose to deposit their work in a subject repository held by an alternative institution. Publishers will then establish an embargo period on the article, usually, in the social sciences, 12-18 months (although two significant social science publishers - Cambridge University Press and Sage - currently have, in fact, zero embargo months) before it is made available on an OA basis.

Most journal publishers have moved to adopt Green either in response to the OA climate or (in the UK case) in response to legislative or regulatory decisions. There has until now been much debate about whether this Green OA model will be a 'quasi-permanent' state of affairs or whether it is a transitional state to a Gold OA regime, and, if the latter, whether and at what stage there will be a 'tipping point' where the old subscription-based Green model succumbs to the new APC-based Gold OA model. This is impossible to tell because much depends on both the public-regulatory environment and whether this acts as an incentive toward OA, and on developments in the journals market. With regard to the first (public-regulatory environment), the UK case, as noted above, is instructive and shows the impact on individuals and institutions of public policies that effectively tie $O A$ to career success and future funding. However, there is nothing incompatible between the legislative mandates on researchers' work and their participation in Green OA, meaning that - if OA were only dependent on the regulatory environment - the Green model of OA would likely become a permanent state. It is, therefore, probably more likely to be the second factor (developments in the market) that is more likely to influence a transition beyond Green.

The proliferation of a large number of so-called predatory journals in response to the development of OA was noted above. The question is whether there are any signs of changes taking place in this market place. On the one hand, the most recent data suggest that the growth in predatory journals continues unabated. Shen and Björk (2015) show that the number of predatory OA journals rose from 1,800 to 8,000 between 2010 and 2014 , with the total number of articles published by these journals rising from 53,000 to over 420,000 in the same period. However, the data also show the regional distribution of the publishers and authors to be highly skewed, with Asia and Africa contributing no fewer than 75 per cent of authors. Their conclusion is that 'the problem of predatory OA seems highly contained to just a few countries, where the academic evaluation practices strongly favor international publication, but without further quality checks'.

At the same time, it is increasingly evident that leading, reputable publishers are adjusting their strategies. Previously, they had focused their attention primarily on developing Green OA 'routes' through their existing journals. Now, however, they are entering the OA market more 
directly with new, 'pure' OA journals, based on APCs, with a wide subject brief (so-called 'megajournals') but accompanied with the trappings of quality associated with their subscription-based journals: good editors, editorial boards, refereeing processes and so on,for example, Palgrave Communications, Research $\&$ Politics (Sage).

The combination of these two developments (skewed growth in OA predatory journals and the growth of new 'quality' $O A$ journals from leading publishers) may be gradually changing the nature of market competition. Until now, that competition has been between lower quality (or at least perceived lower quality) Gold OA journals, on the one hand, and thorough-bred Green $O A$, subscription-based journals on the other. What now appears to be emerging is a more complex market competition between a range of high-quality Gold OA journals, existing Green OA journals and a growing number of predatory journals. Furthermore, if this is a form of 'race for credibility' in the journals market, it seems likely that the competition will separate out into two increasingly unrelated (in terms of authors, readers and geography) sectors: one, a mix of high-quality Gold and Green OA journals, with many publishers active in both; and the other a mix of predatory $\mathrm{OA}$ journals in competition for market share.

If so, the danger is of academic associations being left behind, so concerned are they with their existing portfolio of journals, their declining levels of income and the cuts or adjustments that might have to be made in other services to accommodate these changes. Academic associations need, therefore, to be bold, using their prestigious brand of quality, experience in editing journals and strong relationship with publishers, to establish new OA journals with leading publishers which will both provide a new source of income (limited as that will be initially) and also stake a solid claim in a newly emerging

\section{'Academic associations need, therefore, to be bold ...'}

market - and in such a way that it might offset the transitional costs involved in any later change to their existing journals. Academic associations have a reputational stamp of quality associated with their products which - combined with thriving memberships - offer the potential of forging business models with leading publishers that would have the power to establish themselves clearly in what appear to be separating markets - or even to tame the predatory market in the long term. There are already examples of academic associations doing just this. Regional Studies, Regional Science is an OA journal published by the Regional Studies Association in conjunction with Routledge, and the APSA announced its intention, in 2015, to set up an OA journal with Cambridge University Press.

In short, academic associations should not be cowed by OA ideologues whose goal appears to be to cut out the publisher altogether; rather, they should see their existing publishing partners as continuing and future partners in the new OA world. Publishers will continue to add value in all sorts of ways, first and foremost because academic associations will not want, nor can afford, to develop the technology and expertise to host OA journals. At the same time, leading publishers should be looking to academic associations for their experience and expertise in facilitating the production of academic knowledge. There is no reason, therefore, why academic associations and publishers should not continue to be partners in any new OA regime.

\section{CONCLUSION}

OA represents an evident threat to those academic associations whose financial 
success and service to the profession are dependent upon income generated through journals they own and publish in conjunction with publishers. Academic associations have not only become accustomed to a steady, sizeable stream of income from this source but, until recent years, have expanded their organizations on the quiet assumption that the income could only grow. The new reality is that this source of income will not grow, and is very likely to decline. For small academic associations with limited or no funding from journals at all, the impact of these changes is likely to be minimal. For the larger associations with one or more journals, on the other hand, it means re-thinking and maybe reshaping what these associations do as journal income has been an important means of expanding services to their members. ${ }^{6}$

Yet, this is the sort of threat that can also be turned into an opportunity. Rather than simply adjusting their size, shape and services to the new reality, academic associations need to use their most prestigious resource (a thriving membership), their core expertise (facilitating the production of academic knowledge) and their longstanding experience of working with publishers, to consider developing new products in a changing market. The danger, in other words, may be in acting too conservatively in a rapidly changing market. True, it is possible to act prematurely too, yet there is now growing evidence that the OA argument is being won or is already won - as a consequence of a combination of ideological pressure, technological advances, governmental stances and regulatory changes. The tide is therefore changing and academic associations need to take stock, design a strategy and be bold ... if they are not to be beached.

\section{Acknowledgements}

The author would like to thank David Mainwaring and an anonymous referee for their comments and suggestions on an earlier draft of this article. The views expressed in the article are those of the author and not necessarily of the European Consortium of Political Research (ECPR).

\section{Notes}

1 'Trustees and Financial Report', Years 2000, 2001, 2014: https://www.psa.ac.uk/psa/about-us/ annual-reports.

2 Although there are exceptions, especially where government regulatory action has been significant, for example, Britain and the Netherlands.

3 It is difficult to draw concrete examples without analyzing several associations in depth, but the University Association for the Contemporary European Studies (UACES) might be a case in point: as publisher of a leading journal (Journal of Common Market Studies), it is commonly recognized as the most active academic association in a field (EU studies) in which competing organizations exist. In addition, the case of The Sociological Review, which was not owned by an academic association, is perhaps instructive. A surplus of $£ 1.2$ million was (unknowingly) built up through no action being taken by its owners to re-invest the profit made each year in the discipline, http://www.timeshighereducation.co.uk/news/ journal-board-in-the-dark-over-1m-surplus/2018611.article.

4 Although it is not clear whether, in these figures, journals published on behalf of academic associations by commercial publishers are included.

5 For a characterization of 'predatory' journals, see Beall (2015) and for Beall's List of 'potential, possible or probable predatory scholarly open-access publishers', http://scholarlyoa.com/publishers/.

6 It is noteworthy that the UK's Political Studies Association, in November 2014, set up two commissions ('Reaching Out' and 'Adding Depth') 'to undertake a fundamental review of how the PSA operates in terms of membership groups, the educational journey, member services and a host of other issues'. Part of the context is described as, 'Traditional funding models for learned societies are changing, the 
higher-education environment is increasingly complex and the services and support structures provided to members must evolve accordingly'. http://www.psa.ac.uk/psa/chairs-commissionsreaching-out-and-adding-depth.

\section{References}

Beall, J. (2015) 'Criteria for determining predatory open access publishers', 31 January (3rd edn), https:// scholarlyoa.files.wordpress.com/2015/01/criteria-2015.pdf.

Beverungen, A., Böhm, S. and Land, C. (2012) 'The poverty of journal publishing', Organization 19(6): 929-938, http://org.sagepub.com/content/19/6/929, accessed 22 November 2014.

Esposito, J. (2013) 'Open access and professional societies', The Scholarly Kitchen, available at: http:// scholarlykitchen.sspnet.org/2013/08/01/open-access-and-professional-societies, accessed 1 August 2013.

ECPR [European Consortium of Political Research]. (2015) 'Review of activities 2012-2015', available at: www.ecpr.eu.

Monbiot, G. (2011) 'Academic publishers make Murdoch look like a socialist'. The Guardian 29 August, available at: http://www.theguardian.com/commentisfree/2011/aug/29/academic-publishersmurdoch-socialist.

PSA [Political Studies Association]. (2014) 'Independent review of the implementation of RCUK policy on open access. Response of the Political Studies Association of the United Kingdom', available at: http://www.psa.ac.uk/sites/default/files/Independent Review of the Implementation of RCUK Policy on Open Access-PSA Response-11.9.14.pdf.

Shen, C. and Björk, B.-C. (2015) "Predatory' open access: A longitudinal study of article volumes and market characteristics', BMC Medicine 13: 230, doi:10.1186/s12916-015-0469-2.

Velterop, J. (2005) Open Access Publishing and Scholarly Societies: A Guide, New York: Open Society Institute.

Working Group on Expanding Access to Published Research Findings. (2012) 'Accessibility, sustainability, excellence: How to expand access to research publications', available at: http://www.researchinfonet .org/wp-content/uploads/2012/06/Finch-Group-report-FINAL-VERSION.pdf, accessed 10 January 2015.

\section{About the Author}

Martin J. Bull is Professor of Politics at the University of Salford and Director of the European Consortium of Political Research.

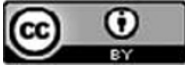

This work is licensed under a Creative Commons Attribution 3.0 Unported License. The images or other third party material in this article are included in the article's Creative Commons license, unless indicated otherwise in the credit line; if the material is not included under the Creative Commons license, users will need to obtain permission from the license holder to reproduce the material. To view a copy of this license, visit http://creativecommons.org/licenses/by/3.0/ 